\title{
Contribution of extreme daily precipitation to total rainfall over the Arabian Peninsula
}

\author{
Mansour Almazroui ${ }^{\mathrm{a}, *}$, Sajjad Saeed ${ }^{\mathrm{a}, \mathrm{b}}$ \\ ${ }^{a}$ Center of Excellence for Climate Change Research/Department of Meteorology, King Abdulaziz University, Jeddah, Saudi Arabia \\ ${ }^{\mathrm{b}}$ Department of Earth and Environmental Sciences, University of Leuven (KU Leuven), Leuven, Belgium
}

\section{A R T I C L E I N F O}

\section{Keywords:}

Extreme precipitation events

Regional climate model

RegCM4

Arabian Peninsula

\begin{abstract}
A B S T R A C T
This study examines the relative contribution of extreme daily precipitation events (RR > 99th percentile) to accumulated rainfall over the Arabian Peninsula in current and future climates. Both gridded observations and model simulation data are analyzed. Observations reveal that the extreme daily precipitation events contribute nearly $40 \%(70 \%)$ to the accumulated amount of rainfall in the wet (dry) regions of the Peninsula for the period 1970-1999. The regional climate model simulations show a large overestimation of the annual mean rainfall in the present climate. However, the model data also depicts almost an enhanced contribution of extreme daily precipitation events to the accumulated rainfall over the Peninsula. In agreement with observations, the simulated extreme precipitation events show a small (large) contribution to total rainfall in the wet (dry) regions. The relative contribution of extreme daily precipitation events to total rainfall increases over the southern and central parts of the Peninsula in case of the future climate. We also found an increase in the accumulated amount of simulated precipitation associated with extreme events in the future climate when compared to the reference period. This indicates that extreme events are likely to become more intense over the Peninsula in the future. The results indicate an increase in daily precipitation intensities over the Arabian Peninsula in the future. The results presented in this study highlight that a better understanding of extreme precipitation events and their regional distribution over the Arabian Peninsula currently and in the future is essential for judicious socio-economic planning for the region.
\end{abstract}

\section{Introduction}

The Arabian Peninsula is surrounded by water bodies on three sides and consists of the countries of Yemen, Oman, United Arab Emirates, Qatar, Bahrain, Kuwait and Saudi Arabia. The region experiences tropical and subtropical conditions with an arid desert climate or arid steppe climate and has a very low annual mean precipitation (Edgell, 2006; Almazroui, 2011). Saudi Arabia occupies the largest part (more than $80 \%$ ) of the Arabian Peninsula (Almazroui, 2012a). Observational records reveal a decreasing trend in precipitation over Saudi Arabia in recent decades ( $47.8 \mathrm{~mm} /$ decade, Almazroui et al., 2012). On the other hand, the number of extreme precipitation events has increased remarkably in recent decades (Almazroui, 2013). According to the Fifth Assessment Report of the Intergovernmental Panel on Climate Change (IPCC), the frequency and intensity of precipitation extremes are likely to increase in most parts of the world in the future (IPCC, 2013). Extreme precipitation events have a large influence on many socio-economic factors of countries through flooding, infrastructural damage and even human fatalities. For realistic planning purposes, better understanding and quantification of these extremes, both currently and in the future, are essential.

The occurrence of extreme precipitation over the Arabian Peninsula is infrequent and highly variable. There are very few studies that specifically address precipitation variability and extremes over this region (e.g. Almazroui et al., 2014; Islam et al., 2015; Donat et al., 2014; Hasanean and Almazroui, 2015). Hasanean and Almazroui (2015) showed that rainfall over Saudi Arabia varies seasonally. Seasonal analysis of rainfall over Saudi Arabia shows that most rainfall is received in winter and spring. The southwest of the Arabian Peninsula receives rainfall in almost all seasons, whereas, the northern part receives much less rainfall in summer (Hasanean and Almazroui, 2015). In the Arabian Peninsula, extreme precipitation events occurred very rarely in past, but their frequency and intensity has increased in recent decades. Extreme events make important contributions to the total annual rainfall. There is a shortage of studies addressing extreme precipitation specifically over the Arabian Peninsula in the literature. Vries

\footnotetext{
* Corresponding author at: Center of Excellence for Climate Change Research/Department of Meteorology, King Abdulaziz University, Jeddah 21589, Saudi Arabia.

E-mail address: mansour@kau.edu.sa (M. Almazroui).
} 
et al. (2016) studied three specific extreme events over Saudi Arabia which occurred in autumn, winter and spring. In all three cases, they found strong tropical-extratropical interactions whereby mid-latitude forcing instigated an incursion of tropical moisture over the Arabian Peninsula fueling heavy rainfall.

In some recent studies (e.g. Almazroui et al., 2016; Almazroui et al., 2017a, 2017b), based on CMIP3 and CMIP5, climate model simulations projected enhanced positive (negative) changes in mean precipitation over southern (northwestern) parts of the Arabian Peninsula by the end of the 21st century. The extent to which precipitation from extreme events contributes to the total amount of rainfall over the Arabian Peninsula in the present climate has not yet been assessed. Moreover, how will this contribution change in the future over the Arabian Peninsula? The present study addresses these questions by analyzing the observational and model simulation data.

The paper is organized as follows: the data and methodology is outlined in the next section. Section 3 examines the observational data to determine the contribution of extreme daily events to total rainfall over the Arabian Peninsula. The contribution of simulated extreme daily events to total rainfall in the present climate is given in Section 4. Changes in contribution in the future are simulated under two future Representative Concentration Pathways, RCP4.5 and RCP8.5, and illustrated in Section 5. The conclusions are drawn in the last section.

\section{Data and methodology}

In this study, both observational and model simulation datasets are used. First, we analyzed the gridded APHRODITE precipitation dataset (Yatagai et al., 2012) for the period 1970-1999. The APHRODITE dataset is available with a horizontal resolution of $0.25^{\circ} \times 0.25^{\circ}$ resolution. This dataset is mainly developed for the Asian region and covers the Arabian Peninsula above $15^{\circ} \mathrm{N}$. We therefore analyzed another observational dataset for daily precipitation with a coarse resolution $\left(0.1^{\circ} \times 0.1^{\circ}\right)$ obtained from CPC Global Unified Precipitation for the period 1979-2016. The CPC dataset was provided by the NOAA/OAR/ ESRL PSD, Boulder, Colorado, USA via their website (http://www.esrl. noaa.gov/psd/). In order to examine the contribution of extreme daily precipitation events to the total annual rainfall over the Arabian Peninsula in the future, climate model simulations performed with version 4 (RegCM4.7) of a regional climate model were also used. The RegCM4.7 was developed by the Abdus Salam International Centre for Theoretical Physics (ICTP), Trieste, Italy. More detailed information about the RegCM4 is available in Giorgi et al. (2012). RegCM4 offers several options for physical parameterization and land surface schemes. Similar to simulations conducted by Almazroui (2016), the model simulations performed at a $0.25^{\circ}$ degree resolution in this study use a)the convective schemes by Grell with Fritsch-Chappell closure (GFC; Fritsch and Chappell, 1980a, 1980b)- the Community Land Model (CLM; Oleson et al., 2008) to represent various aspects of land use. The model is forced with ERSST, the Extended Reconstructed Sea Surface Temperature data obtained from the National Climate Data Centre (NCDC). The effective domain covers an area from $0^{\circ}$ to $45^{\circ} \mathrm{N}$ and $17^{\circ} \mathrm{E}$ to $72^{\circ} \mathrm{E}$ (Islam and Almazroui, 2012). The RegCM4 model is forced with the output from the ECHAM6 model (Atmospheric Global Climate Model of Max Planck Institute for Meteorology, Germany; resolution: $\left.1.80^{\circ} \times 1.80^{\circ}\right)$. The simulations are performed for the present climate (1960-2005) and a future period (2006-2100). Simulations of the future period are performed for two scenarios, namely RCP4.5 and RCP8.5. In order to examine the robustness of the results, additional simulations are performed with RegCM4 model forced with output from the HADGEM model.

Following Saeed et al. (2016), extreme precipitation is defined as daily precipitation intensities falling into the 99th percentile. The precipitation percentiles are computed from the continuous time series which also includes dry days. The relative contribution of extreme precipitation using gridded observational datasets for the period
1979-2016 is examined. Then, the RegCM4 model simulation datasets for the present (1970-1999) and future (2070-2099) periods for two RCPs (RCP4.5 and RCP8.5) are examined. The RegCM4 model simulation datasets are also analyzed for the near future period (2021-2050). However, the difference in the extremes events under the two RCP scenarios is less evident for the near future period as compared to the far future period (2070-2099) (Figs. S4 and S5). This is in agreement with IPCC AR5 which indicate that the extreme events are likely to increase more towards the end of 21 st century. The current study therefore focused on the end century period (2070-2099) under the two RCP scenarios. The significance of the difference in the results for future and present climates is accessed using a $t$-test.

Very extreme precipitation events are examined by analyzing the cumulative distribution of daily rainfall over different parts of the Arabian Peninsula. For this purpose, the Arabian Peninsula is divided into four sub-regions, namely the Northern Arabian Peninsula (NAP: $27-32^{\circ} \mathrm{N} \& 36-46^{\circ} \mathrm{E}$ ), Central Arabian Peninsula (CAP: $21-27^{\circ} \mathrm{N} \&$ $39-49^{\circ} \mathrm{E}$ ), Southern Arabian Peninsula (SAP: $13-20^{\circ} \mathrm{N} \& 43-46^{\circ} \mathrm{E}$ ) and Eastern Arabian Peninsula (EAP: $18-24^{\circ} \mathrm{N} \& 52-58^{\circ} \mathrm{E}$ ). The small variation between the areas of the sub-regions does not affect the overall results. For the four sub-regions, each grid cell for each day is treated as a sample in the distribution. So in total, the sample consists of the grid points for each sub-region multiplied by the number of days in the simulation. For example, in the case of NAP, the number of values in the sample is as follows: $91 \times 46 \times 10,956=45,861,816$. Similarly, the sample sizes for CAP, SAP, EAP are 11,240,856, 18,931,968 and $18,931,968$ respectively. Such large sample frames capture the true information about the daily precipitation extremes as they occur in each grid cell. This information might be overlooked when the data is averaged over sub-domains. Very extreme events simulated in the present and future climates over the four subregions of the Arabian Peninsula are also examined. A very extreme precipitation event is defined as an event where daily rainfall exceeds $50 \mathrm{~mm} \mathrm{day}^{-1}$ in a grid cell. A cumulative distribution curve is plotted for that part of the sample where daily rainfall rates exceed this threshold $\left(50 \mathrm{~mm}_{\text {day }}{ }^{-1}\right)$. The upper limit of precipitation used to define the very extreme events is subjective and a small variation in this limit does not affect the overall results.

\section{Contribution of extreme daily events to total precipitation from observed data}

The observed APHRODITE annual mean precipitation (mm year ${ }^{-1}$ ) distribution over the Arabian Peninsula for the period 1970-1999 is shown in Fig. 1a. The annual mean precipitation during this period varied from $0 \mathrm{~mm}$ to more than $180 \mathrm{~mm}$ (Fig. 1a). The southern mountainous belt extending from Yemen to Saudi Arabia; the Central and adjoining northern parts of Saudi Arabia; the United Arab Emirates; and adjacent parts of Oman received the highest amount of annual mean rainfall (between 70 and $180 \mathrm{~mm}$ year $^{-1}$ ). For brevity, these areas are referred to as wet regions. On the other hand, the Rub Al Khali and the An-Nafud deserts in Saudi Arabia receive the lowest amount of annual mean rainfall $\left(\sim 10-70 \mathrm{~mm}\right.$ year $\left.^{-1}\right)$. These regions (i.e. the Rub $\mathrm{Al} \mathrm{Khali} \mathrm{and} \mathrm{An-Nafud} \mathrm{deserts)} \mathrm{are} \mathrm{referred} \mathrm{to} \mathrm{as} \mathrm{dry} \mathrm{regions} \mathrm{(Fig.} \mathrm{1a).}$

Fig. 1b shows the contribution of extreme daily precipitation events (RR $>$ 99th percentile) to the total rainfall over the Arabian Peninsula during the period 1970-1999. Extreme daily precipitation events contributed a large proportion $(20-70 \%)$ of the total rainfall over the Arabian Peninsula during the period examined (Fig. 1b). The observed data indicates that extreme daily precipitation events contributed $20-40 \%$ of the total annual rainfall that occurred in the wet regions. By comparison, the contribution of extreme daily precipitation events to total rainfall increased dramatically in the dry regions where it reaches $70 \%$ (Fig. 1b). This is logical as the dry regions receive a very small amount of rainfall and so these small number of events (1\% of the data) will tend to fall into the category of extremes events. For this reason, 

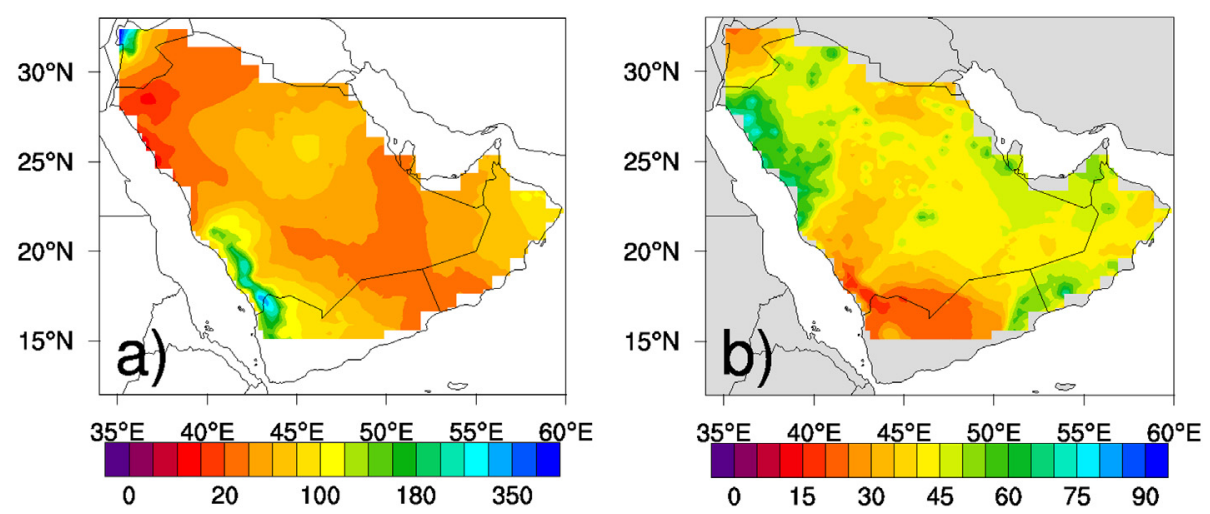

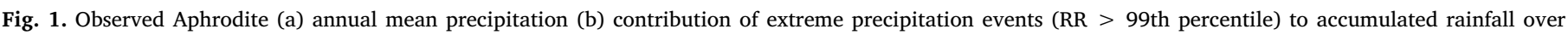

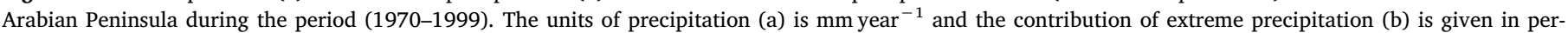
centage.

the contribution of extreme daily precipitation events is very high in the dry regions. We also examined this issue in the CPC datasets. The observed CPC annual mean precipitation $\left(\mathrm{mm} \mathrm{year}^{-1}\right)$ for the period 1979-2016 is shown in Fig. S1a. The CPC annual mean precipitation over the Arabian Peninsula varied from 0 to $180 \mathrm{~mm}$ year $^{-1}$ for this period (Fig. S1a). In line with the APHRODITE dataset, the southern mountainous region of Saudi Arabia close to Yemen, the northeastern parts of Oman and the Arab Emirates all show the highest amount of annual mean rainfall ( $\sim 100-180$ mm year $\left.^{-1}\right)$. The Rub Al Khali and the An-Nafud deserts in Saudi Arabia receive the lowest amount of annual mean rainfall (less than $50 \mathrm{~mm}_{\text {year }}{ }^{-1}$ ) compared to the wet regions. Compared to the APHRODITE precipitation data, the CPC precipitation data shows that extreme precipitation events contribute greatly to the total rainfall amount over the Arabian Peninsula during the studied period (Fig. S1b). The CPC data shows that precipitation from extreme events contributed 70 (90) percent of the total precipitation that occurred in the wet (dry) regions. The large difference between the two observational datasets may be due to the different horizontal resolutions, time period and the interpolation methods. However, it is evident from both observational datasets that extreme precipitation events contribute greatly to the total rainfall over the Arabian Peninsula. Furthermore, the proportion contributed is greater in the dry regions than the wet regions. The next section describes the contribution of extreme daily events to total annual rainfall in the RegCM4 simulation dataset for the present climate.

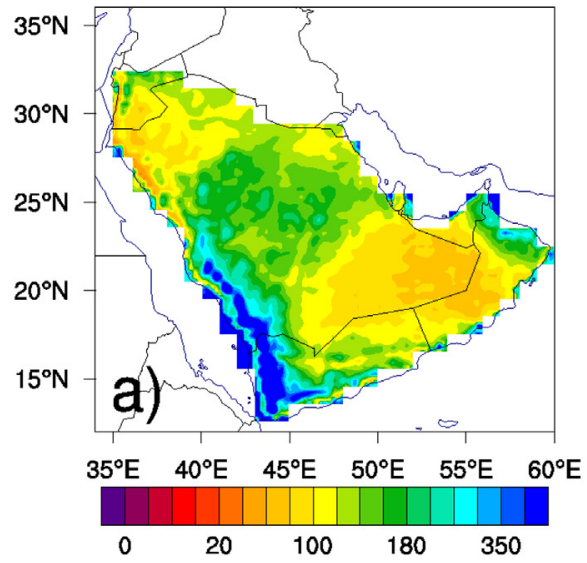

\section{Simulated contribution of extreme daily events to total rainfall} for the present climate

Before analyzing the contribution of simulated extreme daily precipitation events to the total annual rainfall in the present climate, we assessed the performance of the RegCM4 model over the Arabian Peninsula. Fig. S2 shows the observed and simulated annual mean precipitation and wet and heavy rainfall days. Here, a wet day is defined as one when the accumulated daily precipitation is equal to or above $1 \mathrm{~mm}$ while a heavy rainfall day is defined as one where the accumulated daily precipitation is $10 \mathrm{~mm}$ or more. The RegCM4 model simulates reasonably well the spatial distribution of the annual mean precipitation on wet and heavy rainfall days compared to observations. Both observation and simulation data show enhanced (reduced) annual mean rainfall and more wet and heavy rainfall days in the southern mountainous and central part (the Rub Al Khali and the An-Nafud deserts) of the Arabian Peninsula. However, the model overestimates the annual mean rainfall and the wet and heavy rainfall days over the Arabian Peninsula. In some areas, the overestimation is nearly twice that of the observed values. The model also shows a slight shift in the Rub Al Khali dry region to the northeast compared to observations. The objective of this study is not to directly compare model simulations with observations but to examine the contribution of extreme daily precipitation to total rainfall over the Arabian Peninsula both in the present and future climate. Therefore, we will not further investigate the causes of the biases in the RegCM4 simulations over the Arabian Peninsula in this study. The RegCM4 model has already been tested and used to study the climate and extreme events over the Arabian

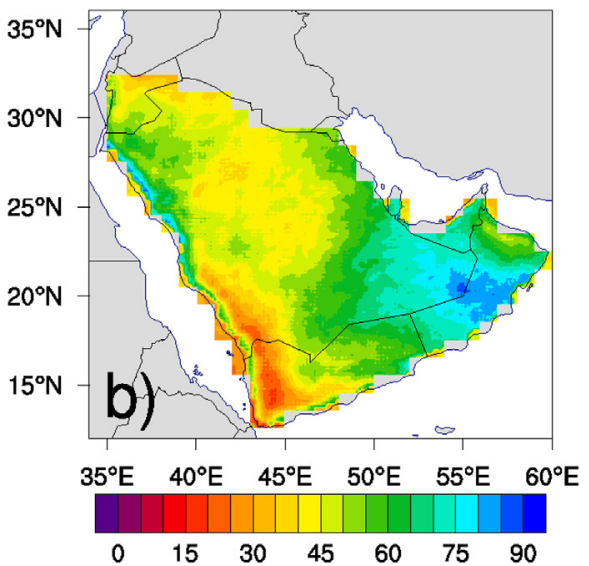

Fig. 2. Same as Fig. 1, except showing the RegCM4 simulation data for present day climate (1970-1999). The units of precipitation (a) is mm year ${ }^{-1}$ and the contribution of extreme precipitation (b) is given in percentage. 
Peninsula (e.g., Almzaroui et al., 2017c, 2017d; Almazroui, 2012b).

Fig. 2a shows the simulated annual mean rainfall over the Arabian Peninsula for the present climate (1970-1999). The RegCM4 simulation shows (Fig. 2a) slight differences in the spatial pattern of annual mean precipitation compared to the observations (Fig. 1a). In line with observations, the model shows enhanced annual mean precipitation over the southern mountainous region and central parts of the Peninsula. However, the model simulation of annual mean precipitation is largely overestimated. Fig. 2b shows the contribution of simulated extreme daily precipitation events to total precipitation over the Arabian Peninsula for the period 1970-1999. In line with observations (Fig. 1b; Fig. S1b), the RegCM4 simulation shows that most of the Arabian Peninsula receives a larger contribution to total rainfall from the daily extreme daily precipitation (Fig. 2b). The simulated contribution of extreme daily precipitation events to total rainfall varies from $20 \%$ to more than $70 \%$ over the Arabian Peninsula. The simulated data show that the annual accumulated precipitation in the dry (wet) regions receive the highest (lowest) contribution from extreme precipitation events and this is in agreement with observations. It is yet not known whether the contribution made by extreme precipitation events to total annual rainfall remains the same or changes under different future scenarios. This issue is underpinned in the next section.

\section{Future changes in the contribution of extreme events to total rainfall}

In this section, the contribution of extreme daily precipitation to total rainfall over Saudi Arabia is examined in the context of future (2070-2099) climate based on the Representative Concentration Pathways RCP4.5 and RCP8.5 scenarios. The RegCM4 simulations show a spatial pattern of annual mean rainfall over Saudi Arabia in the future climate (Fig. 3a, c) similar to the present day climate (Fig. 2a). The simulated contribution of extreme precipitation to total rainfall
(Fig. 3b, d) for the period 2070-2099 also resembles the contribution in the present day climate (Fig. 2b). The extreme precipitation contribution varies over the Arabian Peninsula. Similar to the present-day climate simulation, the extreme precipitation contribution is large (small) in the dry (wet) regions. In the case of the RCP 8.5 scenario (Fig. 3c, d), the simulated patterns resemble the RCP4.5 scenario, however, these patterns are amplified in the case of the RCP8.5 scenario. Additional RegCM4 simulation forced with output from HADGEM shows nearly similar spatial distribution of extreme precipitation contribution to the total rainfall in both present and future climate (Fig. S3). However, the RegCM4 simulations forced with HADGEM show more amplification in the extreme precipitation contribution as compared the RegCM4 simulations forced with ECHAM6 model (Fig. S3). For brevity, the present study focused on RegCM4 simulations forced with output from ECHAM6 model. From the above discussion, it is evident that, irrespective of the biases in the climate model, the simulations of extreme precipitation events contributes greatly to total precipitation over the Arabian Peninsula in both present and future climates. These findings are further supported by the observational dataset in the present climate.

The 5th assessment report of IPCC reveals that the extremes events will increase in intensity and frequency in the future. Changes in the amount of accumulated daily precipitation in the future and of extreme daily precipitation over the Arabian Peninsula are examined in the RCP4.5 and 8.5 scenarios (Fig. 4). For the period 2070-2099, the RegCM4 model simulations show a remarkable increase in the accumulated daily precipitation (Fig. 4a, c) and extreme precipitation amounts (Fig. 4b, d) over the Arabian Peninsula in both the RCP4.5 and RCP8.5 scenarios. The southern, eastern and central parts of the Arabian Peninsula present a large increase in the total amount of daily rainfall in the future period (2070-2099) compared to the present day climate (1970-1999). The total amount of precipitation associated with extreme events increases over most of the Arabian Peninsula (Fig. 4b, d)
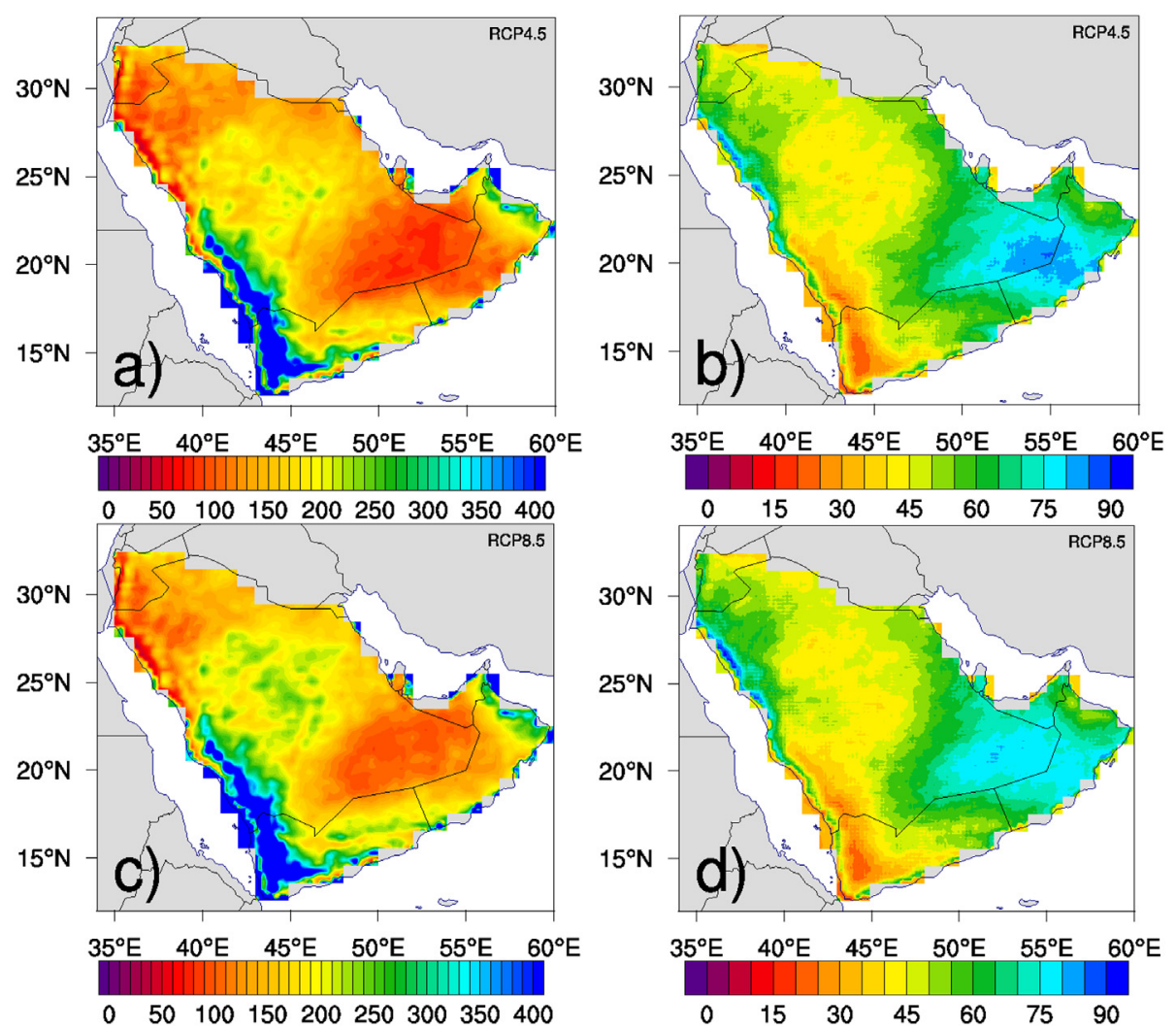

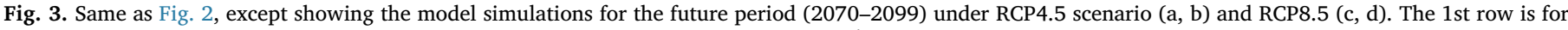

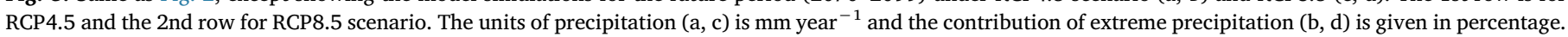




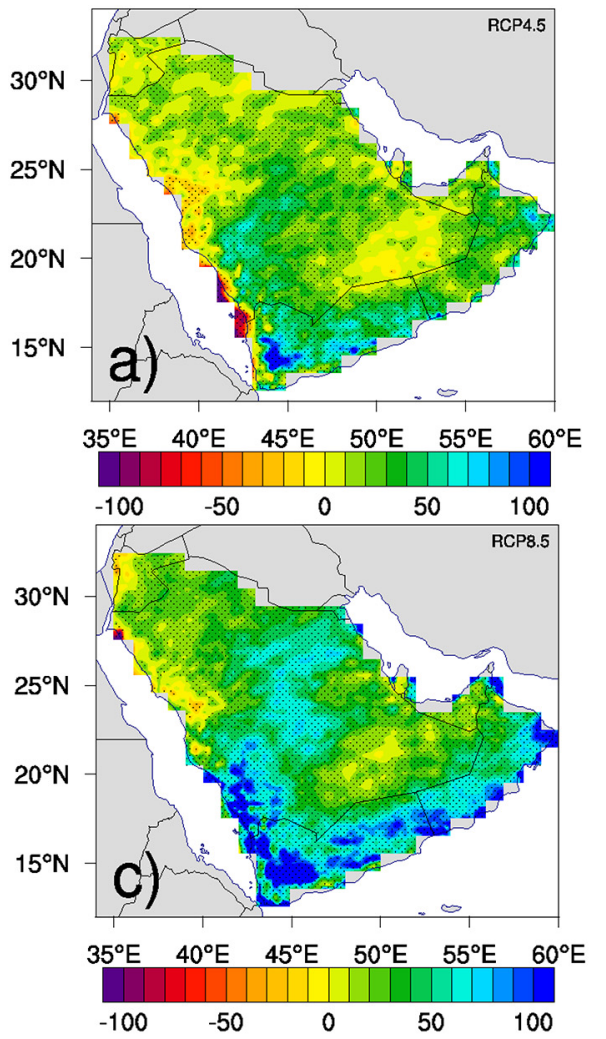

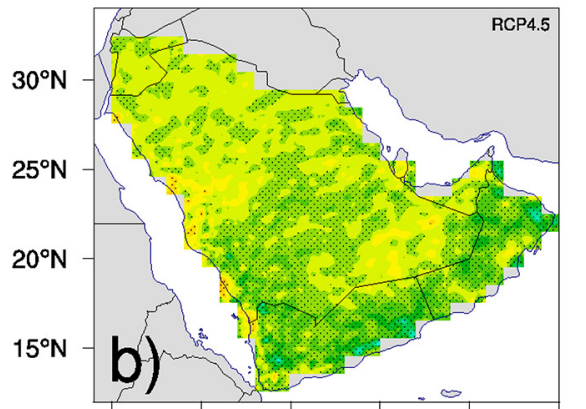

Fig. 4. Future change in the (a) daily accumulated precipitation (b) extreme daily precipitation (RR > 99th pctl) over the Arabian Peninsula. The future changes are computed for the period 2070-2099 w.r.t. 1970-1999, under RCP4.5 scenario. (c, d) same as (a, b) except showing results for RCP8.5 scenario. The 1st row is for RCP4.5 and the 2nd row for RCP8.5 scenario. The unit of precipitation is $\mathrm{mm}$. The dotted areas shows the changes that are significant at $99 \%$ confidence level based on $t$ test. by the end of 21st century. The change in extreme daily precipitation in the future is more pronounced under the RCP 8.5 scenario. In this case, most of the Arabian Peninsula shows increased total rainfall compared to the present climate. Since total number of extreme precipitation events represent 1\% (RR > 99th percentile) of the total data used in both present and future climate, an increase in the total amount of precipitation associated with these extreme $1 \%$ events indicates that they will be more intense over this region in the future. This is in agreement with the IPCC findings that precipitation extremes in the future will be more intense in some regions. This is because, in a warmer climate, the atmosphere is able to hold more moisture causing extreme events to be more intense compared to those in the present climate.

To further examine this issue, we investigated the changes in extreme daily precipitation events over four different sub-regions of the Arabian Peninsula. In this case, we extracted the data from each grid point within each analysis domain for the NAP, CAP, SAP and EAP. For the four subregions, each day and grid cell is treated as a sample of the distribution. So in total, the sample consists of the grid points in each subregion multiplied by the number of days in the simulation. For example, the NAP sample consists of $45,861,816$ values. This sample contains the complete information about the daily extreme events that each grid cell encountered during the above period over the NAP domain. This information might be lacking when the data is averaged over subdomains. The same is true for the other subdomains. We carried out further analysis on four subregions using a large number of sample data as explained earlier. Fig. 5a shows the 99th percentile values for present and future climate simulations over the NAP, CAP, SAP and EAP. Compared to the simulation for the present climate, the 99th percentile value increased in the case of future simulations under both the RCP4.5 and RCP8.5 scenarios. Furthermore, the 99th percentile values are higher for the SAP region than the other areas. Fig. $5 \mathrm{~b}$ shows that the contribution of extreme precipitation varies from $40 \%$ for SAP to $75 \%$ for EAP. This is in agreement with Figs. $2 b$ and $3 b, d$.

We also examined the distribution of particularly extreme events in the present and future climate over the Arabian Peninsula. Fig. 6 shows the cumulative distribution for very extreme events above the threshold of $50 \mathrm{~mm} \mathrm{day}^{-1}$. In all cases, the intensity and frequency of very extreme events increased in the future climate when compared to the reference period. In the extreme scenario (RCP8.5), some grid cells in the NAP received $\sim 350 \mathrm{~mm}^{\text {day }}{ }^{-1}$ during the period $2070-2099$. For CAP, SAP and EAP this amount is $\sim 275 \mathrm{~mm} \mathrm{day}^{-1}, \sim 360 \mathrm{~mm} \mathrm{day}^{-1}$ and $\sim 550 \mathrm{~mm}^{-1 a y}{ }^{-1}$, respectively. We cannot gauge the uncertainty in the above values as a single model output was used for the analysis. Further studies are therefore needed to examine this issue in more detail. We also examined future changes in daily precipitation intensities over the four subregions (Fig. 7). In this case, we first arranged the data in ascending order and then computed the difference in the daily intensities between the future and present climate. It should be noted that the difference in the daily precipitation intensities for the future and present climates increases linearly. The difference is larger (smaller) for high (low) intensity events. This is a further indicator that high intensity events will become more intense in the future. The SAP and EAP show large increases in high intensity precipitation events in the future climate compared to the reference period. We also noticed an increase in the total amount of precipitation associated with extreme (1\%) events in the future compared to the reference period (Fig. 8). This increase is larger under the RCP8.5 scenario. The total amount of precipitation associated with extreme (1\%) events increases most over the SAP and EAP regions. From the above discussion, it is evident that extreme precipitation events will become more intense over the Arabian Peninsula in the future. This is true even if the number of future precipitation extreme events is the same as in the present climate. The increase in intensity of extremes in the future will bring more rainwater to areas, causing more severe flash flooding and infrastructural damage in the region.

\section{Summary and concluding remarks}

In this study, both gridded observations and regional climate model 

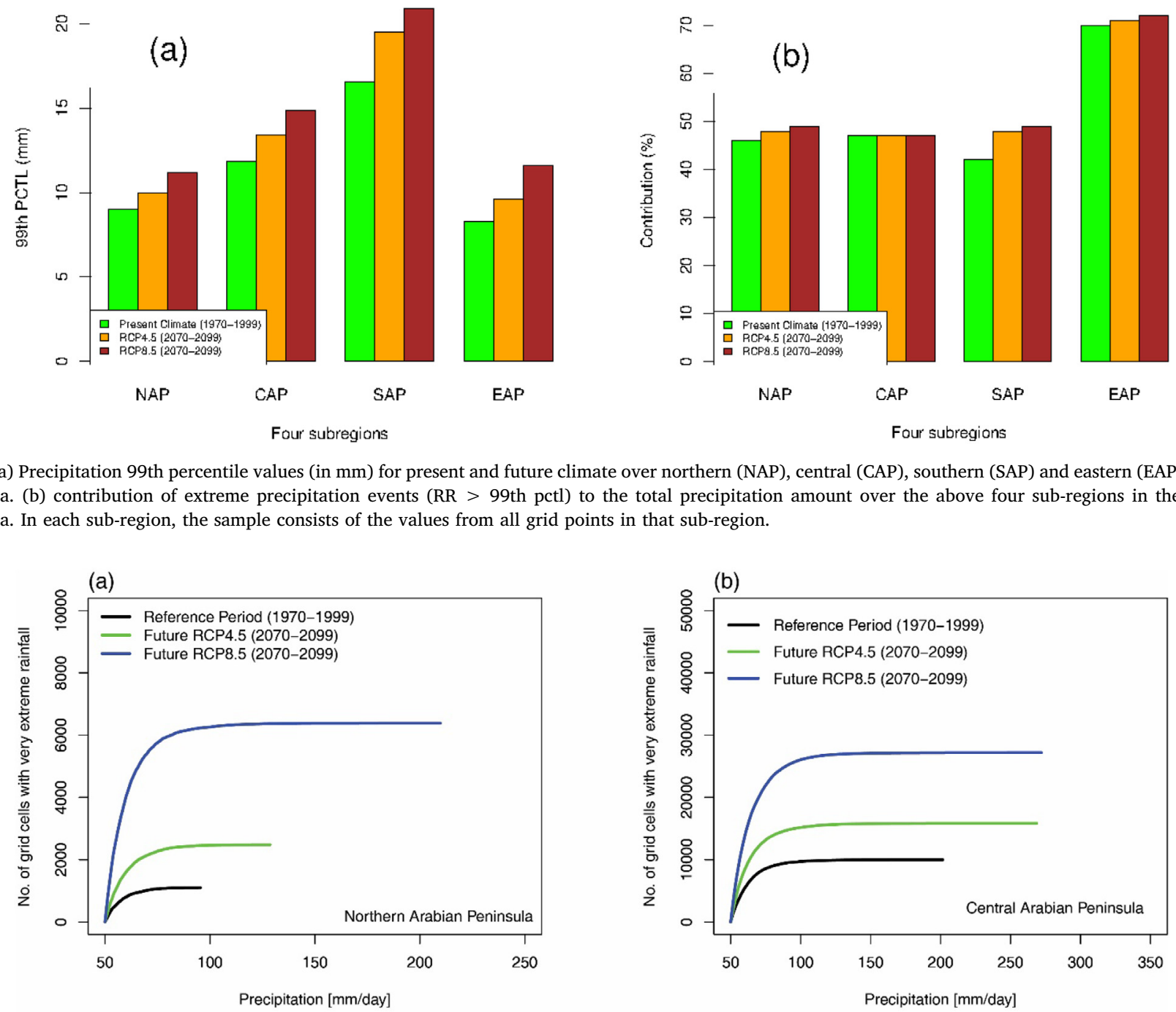

Fig. 5. (a) Precipitation 99th percentile values (in mm) for present and future climate over northern (NAP), central (CAP), southern (SAP) and eastern (EAP) Arabian Peninsula. (b) contribution of extreme precipitation events (RR > 99th pctl) to the total precipitation amount over the above four sub-regions in the Arabian Peninsula. In each sub-region, the sample consists of the values from all grid points in that sub-region.
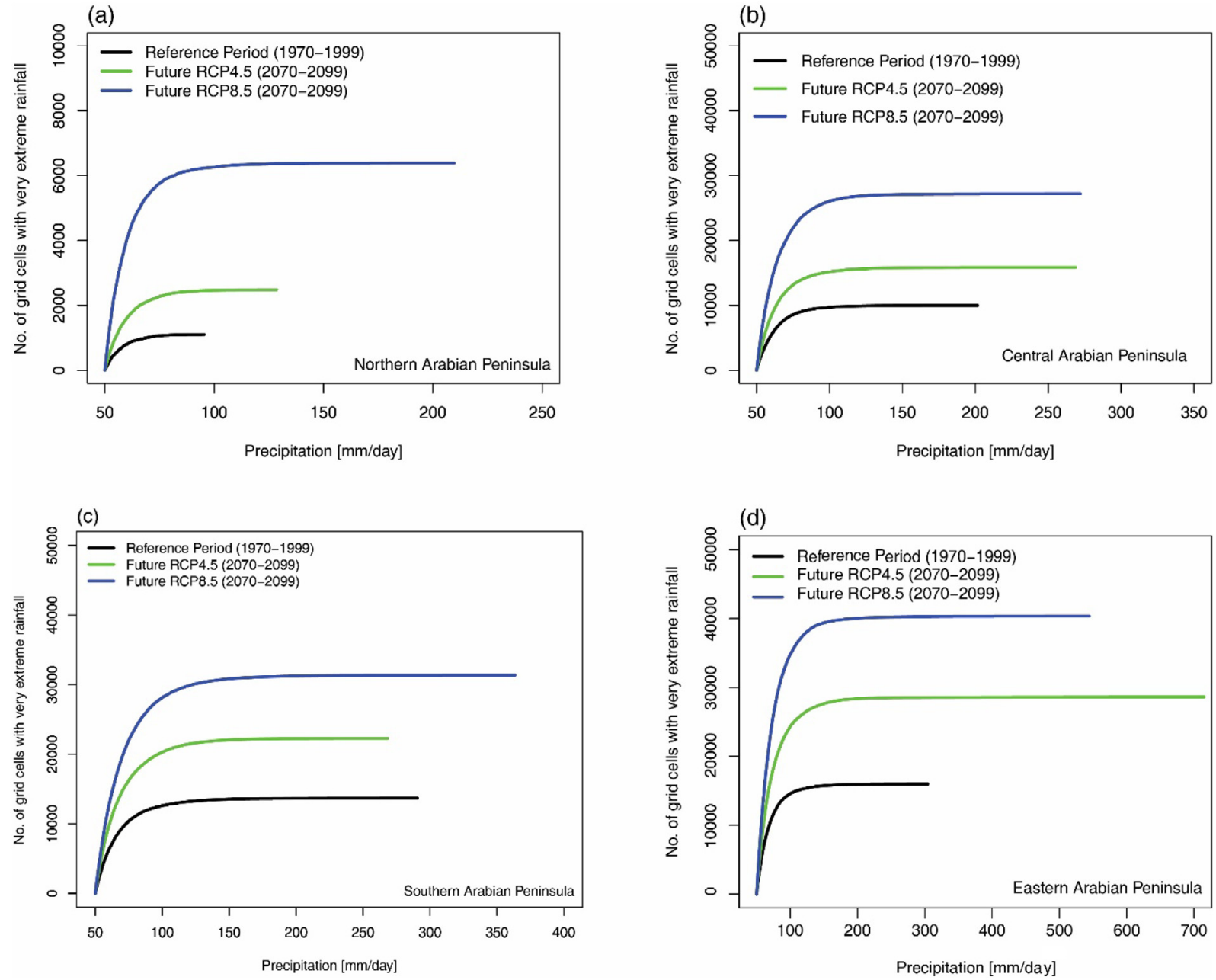

Fig. 6. Cumulative distribution of the simulated daily precipitation extreme events (above $50 \mathrm{~mm} \mathrm{day}^{-1}$ ) over (a) Northern Arabian Peninsula (b) Central Arabian Peninsula (c) Southern Arabian Peninsula (d) Eastern Arabian Peninsula. The black, green and blue lines show the present climate (1970-1999) and Future RCP4.5 and RCP8.5 (2070-2099) simulations. In each sub-region, the sample consists of the values from all grid points in that sub-region. (For interpretation of the references to colour in this figure legend, the reader is referred to the web version of this article.)

simulation data are used to examine the relative contribution of extreme daily precipitation events ( $R R>99$ th percentile) to total rainfall over the Arabian Peninsula. Observations reveal that extreme daily precipitation events contribute largely to the accumulated rainfall amounts over the Arabian Peninsula. The contribution of daily extremes to the accumulated rainfall level varies regionally. Extreme daily 


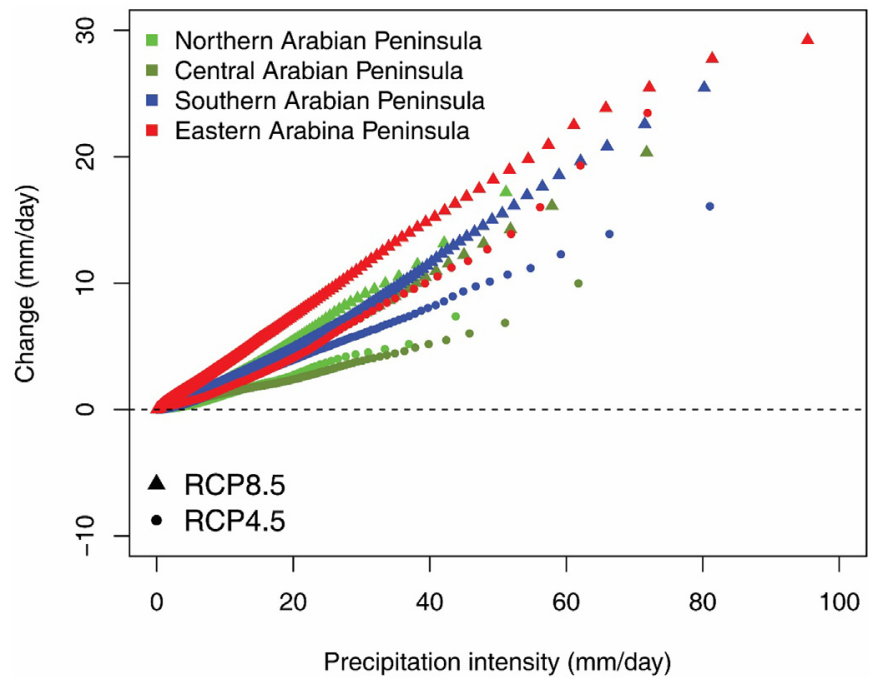

Fig. 7. Future change in the simulated daily precipitation intensities over four sub-regions of the Arabian Peninsula. The future changes are computed for the period 2070-2099 w.r.t. 1970-1999, under RCP4.5 and RCP8.5 scenarios. The green, olive drab, blue and red colors shows change in the daily intensities over the Northern, Central, Southern and Eastern Arabian Peninsula respectively. The unit of precipitation is $\mathrm{mm} \mathrm{day}^{-1}$. (For interpretation of the references to colour in this figure legend, the reader is referred to the web version of this article.)

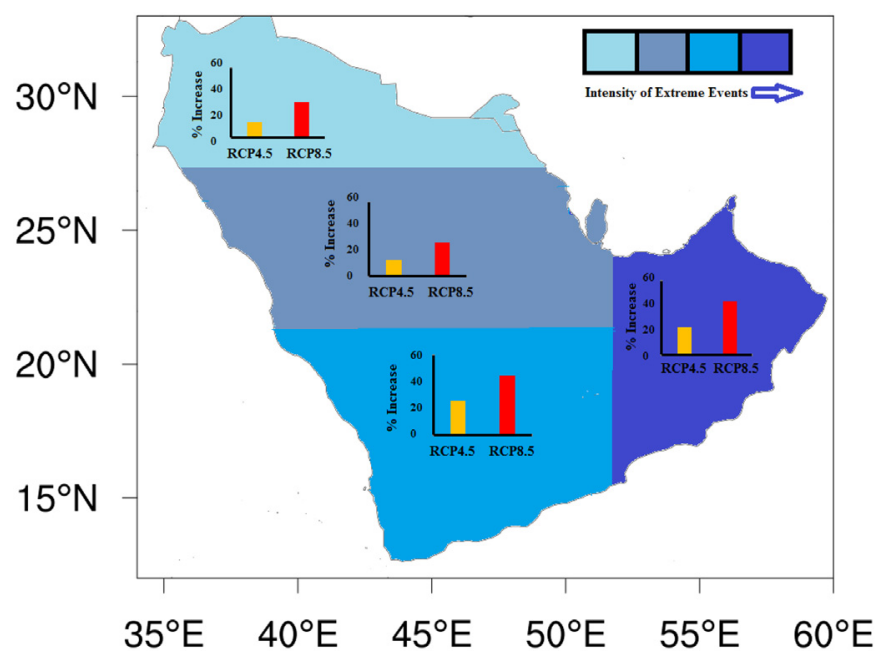

Fig. 8. Map showing the regional variability in the intensity of future extremes over the Arabian Peninsula. The bar plot in each region shows the percentage (\%) increase in extreme precipitation total amount compared to the same from the present climate. The bar plots are obtained for the four subregions defined in the text as Northern Arabian Peninsula (NAP: $27-32^{\circ} \mathrm{N} \& 36-46^{\circ} \mathrm{E}$ ), Central Arabian Peninsula (CAP: $21-27^{\circ} \mathrm{N} \& 39-49^{\circ} \mathrm{E}$ ), Southern Arabian Peninsula (SAP: $13-20^{\circ} \mathrm{N} \& 43-46^{\circ} \mathrm{E}$ ) and Eastern Arabian Peninsula (EAP: $18-24^{\circ} \mathrm{N} \&$ $52-58^{\circ} \mathrm{E}$ ). The shaded areas shows a schematic representation of the spatial variability of intensity of extremes over the Arabian Peninsula. The intensity of extremes increase from West to South and southeastern parts of the Arabian Peninsula.

precipitation events contribute nearly $40 \%$ (70\%) to total rainfall in the wet (dry) regions of the Arabian Peninsula over the period 1970-1999.

In order to examine the contribution of extreme daily precipitation events to the accumulated rainfall total for the 21st century, regional climate model simulations were performed over the Arabian Peninsula with a RegCM4 model, based on two future climate scenarios (RCP 4.5 and RCP8.5). The model-simulated spatial distribution of annual mean precipitation and wet and heavy rainfall days over the Arabian
Peninsula is in agreement with the observations. However, the model data shows large overestimations when compared to observations.

Compared to the reference period, an increase in the total rainfall amount associated with the extreme precipitation (1\%) events is noted over the Arabian Peninsula by the end of the 21st century. This indicates that extreme precipitation events are likely to become more intense and will thus bring more water to the Arabian Peninsula in the future. The cumulative distribution of very extreme events (above $50 \mathrm{~mm}$ day $^{-1}$ ) indicates an increase in the intensity and frequency of such events over the Arabian Peninsula in the future. Moreover, the distribution of daily precipitation intensities also indicates an amplification of high-intensity events by the end of 21st century over the Arabian Peninsula. The southern and eastern parts of the Arabian Peninsula are expected to experience more intense extreme precipitation events by the end of the 21st century compared to the reference period.

The results presented in this study indicate that extreme daily precipitation events will intensify over the Arabian Peninsula in the future climate. This is in agreement with previous studies (e.g., El Kenawy and McCabe, 2017), which found a significant increase in the weather types favoring above-normal rainfall events in this region. Recently, Prein et al. (2017) showed that extreme precipitation is increasing with temperature in moist, energy-limited environments and decreasing in dry, moisture-limited environments. More intense extreme precipitation events in the future will bring enhanced water delivered in short durations possibly causing severe flash flooding and infrastructural damage in the Arabian Peninsula. As the results of the present study are based on single model output, further studies are therefore needed to investigate this issue in more detail. Since extreme precipitation events contribute largely to total rainfall over the Arabian Peninsula, a better understanding of these events in the present climate and reliable future projections of them could help policymakers to judiciously plan the construction of new water reservoirs in this region.

\section{Acknowledgements}

The authors thank the two anonymous reviewers for helpful and insightful comments. The authors would like to acknowledge the Center of Excellence for Climate Change Research (CECCR) for providing funding to carry out this research work. The RegCM4 simulations were performed on the Aziz Supercomputer of King Abdul Aziz University Jeddah, Saudi Arabia. The General Authority for Meteorology and Environmental Protection (GAMEP) is acknowledged for providing surface observations and ICTP, Trieste, Italy, is acknowledged for providing the RegCM4.

\section{Appendix A. Supplementary data}

Supplementary data to this article can be found online at https:// doi.org/10.1016/j.atmosres.2019.104672.

\section{References}

Almazroui, M., 2011. Calibration of TRMM rainfall climatology over Saudi Arabia during 1998-2009. Atmos. Res. 99, 400-414. https://doi.org/10.1016/j.atmosres.2010.11. 006.

Almazroui, M., 2012a. Temperature variability over Saudi Arabia during the period 1978-2010 and its association with global climate indices. JKAU: Met. Env. \& Arid Land Agric. Sci. 23 (1). https://doi.org/10.4197/Met.23-1.6.

Almazroui, M., 2012b. Dynamical downscaling for rainfall and temperature over Arabian Peninsula using RegCM4. Clim. Res. 52, 49-62. https://doi.org/10.3354/cr01073.

Almazroui, M., 2013. Simulation of present and future climate of Saudi Arabia using a regional climate model (PRECIS). Int. J. Climatol. 33, 2247-2259.

Almazroui, M., 2016. RegCM4 in climate simulation over CORDEX-MENA/Arab domain: selection of suitable domain, convection and land-surface schemes. Int. J. Climatol. 36, 236-251.

Almazroui, M., Islam, M.N., Athar, H., Jones, P.D., Rahman, M.A., 2012. Recent climate change in the Arabian Peninsula: annual rainfall and temperature analysis of Saudi Arabia for 1978-2009. Int. J. Climatol. 32, 953-966. 
Almazroui, M., Islam, M.N., Dambul, R., Jones, P.D., 2014. Trends of temperature extremes in Saudi Arabia. Int. J. Climatol. 34, 808-826.

Almazroui, M., Saeed, F., Islam, M.N., Alkhalaf, A.K., 2016. Assessing the robustness and uncertainties of projected changes in temperature and precipitation in AR4 Global Climate Models over the Arabian Peninsula. Atmos. Res. 182, 163-175.

Almazroui, M., Islam, M.N., Saeed, F., Alkhalaf, A.K., Dambul, R., 2017a. Assessing the robustness and uncertainties of projected changes in temperature and precipitation in AR5 Global Models over the Arabian Peninsula. Atmos. Res. 194, 202-213.

Almazroui, M., Saeed, S., Islam, M.N., Khalid, M.S., Alkhalaf, A.K., Dambul, R., 2017b. Assessment of uncertainties in projected temperature and precipitation over the Arabian Peninsula: a comparison between different categories of CMIP3 models. Earth Syst. Environ. 1-12. https://doi.org/10.1007/s41748-017-0012-z.

Almzaroui, M., Islam, M.N., Balkhair, K.S., Sen, Z., Masood, A., 2017c. Rainwater harvesting possibilities under climate change: a basin scale case study over western province of Saudi Arabia. Atmos. Res. 189, 11-23. https://doi.org/10.1016/j. atmosres.2017.01.004.

Almzaroui, M., Balkhair, K.S., Islam, M.N., Sen, Z., 2017d. Climate change impact on monthly precipitation wet and dry spells in arid regions: case study over Wadi Al-Lith basin. Adv. Meteorol. https://doi.org/10.1155/2017/5132895.

Donat, M.G., Peterson, T.C., Brunet, M., King, A.D., Almazroui, M., Kolli, R.K., Boucherf, D., Al-Mulla, A.Y., Nour, A.Y., Attia, Aly.A., Nada, T.A.A., Semawi, M.M., Al Dashti, H.A., Salhab, T.G., El Fadli, K.I., Muftah, M.K., Eida, S.D., Badi, W., Driouech, F., El Rhaz, K., Abubaker, M.J.Y., Ghulam, A.S., Erayah, A.S., Mansour, M.B., Alabdouli, W.O., Al Dhanhani, J.S., Al Shekaili, M.N., 2014. Changes in extreme temperature and precipitation in the Arab region: long-term trends and variability related to ENSO and NAO. Int. J. Climatol. 34, 581-592.

Edgell, H.S., 2006. Arabian Deserts: Nature, Origin, and Evolution. Springer ISBN 978-14020-3970-6. https://www.springer.com/gp/book/9781402039690.

El Kenawy, A.M., McCabe, M.F., 2017. Future projections of synoptic weather types over the Arabian Peninsula during the twenty-first century using an ensemble of CMIP5 models. Theor. Appl. Climatol. 130, 173-189. https://doi.org/10.1007/s00704-0161874-y.

Fritsch, J.M., Chappell, C.F., 1980a. Numerical prediction of convectively driven mesoscale pressure systems, part I, convective parameterization. J. Atmos. Sci. 37, 1722-1733.

Fritsch, J.M., Chappell, C.F., 1980b. Numerical prediction of convectively driven mesoscale pressure systems, part II, mesoscale model. J. Atmos. Sci. 37, 1734-1762. Giorgi, F., Coppola, E., Solmon, F., Mariotti, L., Sylla, M.B., Bi, X., Elguindi, N., Diro, G.T., Nair, V., Giuliani, G., Turuncoglu, U.U., Cozzini, S., Güttler, I., O'Brien, T.A., Tawfik, A.B., Shalaby, A., Zakey, A.S., Steiner, A.L., Stordal, F., Sloan, L.C., Branković, C., 2012. RegCM4: model description and preliminary tests over multiple CORDEX domains. Clim. Res, 52, 7-29.

Hasanean, Hosny, Almazroui, M., 2015. Review rainfall: features and variations over Saudi Arabia. A Rev. Clim. 3 (3), 578-626. https://doi.org/10.3390/cli3030578.

IPCC, 2013. Summary for policymakers. In: Stocker, T.F., Qin, D., Plattner, G.-K., Tignor, M., Allen, S.K., Boschung, J. ... Midgley, P.M. (Eds.), Climate Change 2013: The Physical Science Basis. Contribution of Working Group I to the Fifth Assessment Report of the Intergovernmental Panel on Climate Change. Cambridge University Press, Cambridge, UK and New York, NY.

Islam, M.N., Almazroui, M., 2012. Direct effects and feedback of desert dust on the climate of the Arabian Peninsula during the wet season: a regional climate model study. Clim. Dyn. 39, 2239-2250.

Islam, M.N., Almazroui, M., Dambul, R., Jones, P.D., Alamoudi, A.O., 2015. Long-term changes in seasonal temperature extremes over Saudi Arabia during 1981-2010. Int. J. Climatol. 35, 1579-1592

Oleson, K.W., Niu, G.Y., Yang, Z.L., et al., 2008. Improvements to the Community Land Model and their impact on the hydrological cycle. J. Geophys. Res. 113. https://doi. org/10.1029/2007JG000563.

Prein, A.F., Rasmussen, R.M., Ikeada, K., Liu, C., Clark, M.P., 2017. The future intensification of hourly extremes. Nat. Clim. Chang. 7, 48-52. https://doi.org/10. 1038/nclimate3168.

Saeed, S., Brisson, E., Demuzere, M., Tabrari, H., Willems, P., van Lipzig, N.P.M., 2016 Multidecadal convection permitting climate simulations over Belgium: sensitivity of future precipitation extremes. Atmos. Sci. Lett. https://doi.org/10.1002/asl.720.

Vries, A.J., Feldstein, S.B., Riemer, M., Tyrlis, E., Sprenger, M., Baumgart, M., Fnais, M., Lelieveld, J., 2016. Dynamics of tropical-extratropical interactions and extreme precipitation events in Saudi Arabia in autumn, winter and spring. Q.J.R. Meteorol. Soc. https://doi.org/10.1002/qj.2781.

Yatagai, A., et al., 2012. PHRODITE: constructing a long-term daily gridded precipitation dataset for Asia based on a dense network of rain gauges. Bull. Am. Meteor. Soc. 93, 1401-1415. 